\title{
Right coronary artery supply to a cardiac mass
}

\author{
J. M. Zelis · N. Westphal
}

Published online: 22 August 2019

(C) The Author(s) 2019

A 73-year-old patient with previously percutaneously treated coronary artery disease and a history of smoking was referred for routine preoperative screening in preparation for a transurethral tumour resection. He reported dyspnoea. Physical examination revealed normal cardiac auscultation without signs of heart failure. Echocardiography identified a mass of 56 by $32 \mathrm{~mm}$ in the left atrium (Fig. 1a) near the anterior leaflet of the mitral valve attached to the atrial septum (asterisk). Subsequently, MRI revealed that the mass was a myxoma. Preoperative coronary angiography showed no significant coronary artery stenoses. When contrast was injected into the right coronary artery a clear side branch (Fig. 1b) with contrast blush to a structure in the left atrium was seen, corresponding to a left atrial tumour (asterisk). As is known from the literature, left atrial myxomas are often vascularised by the circumflex artery, closely followed by the right coronary artery $[1,2]$. Complete tumour resection followed, which left the patient in good health.

Conflict of interest J.M. Zelis and N. Westphal declare that they have no competing interests.

Open Access This article is distributed under the terms of the Creative Commons Attribution 4.0 International License (http://creativecommons.org/licenses/by/4.0/), which permits unrestricted use, distribution, and reproduction in any medium, provided you give appropriate credit to the original author(s) and the source, provide a link to the Creative Commons license, and indicate if changes were made.

\section{References}

1. Paelinck BPCV, Vermeersch PHMJ, Convens CG, van Cauwelaert PhA, van den Branden FLJ. Cardiac myxoma in thirteen patients (in Dutch). Ned Tijdschr Geneeskd. 1995;139(38):1931-5.

2. Rahmanian PB, Castillo JG, Sanz J, Adams DH, Filsoufi F. Cardiac myxoma: preoperative diagnosis using a multimodal imaging approach and surgical outcome in a large contemporary series. Interact Cardiovasc Thorac Surg. 2007;6(4):479-83.
J. M. Zelis $(\bowtie) \cdot$ N. Westphal

Department of Cardiology, Catharina Hospital Eindhoven,

Eindhoven, The Netherlands

jo.zelis@catharinaziekenhuis.nl 
Fig. 1 a Echocardiogram showing cardiac mass in left atrium. b Coronary angiogram showing supply to an extra-cardiac mass from the right coronary artery
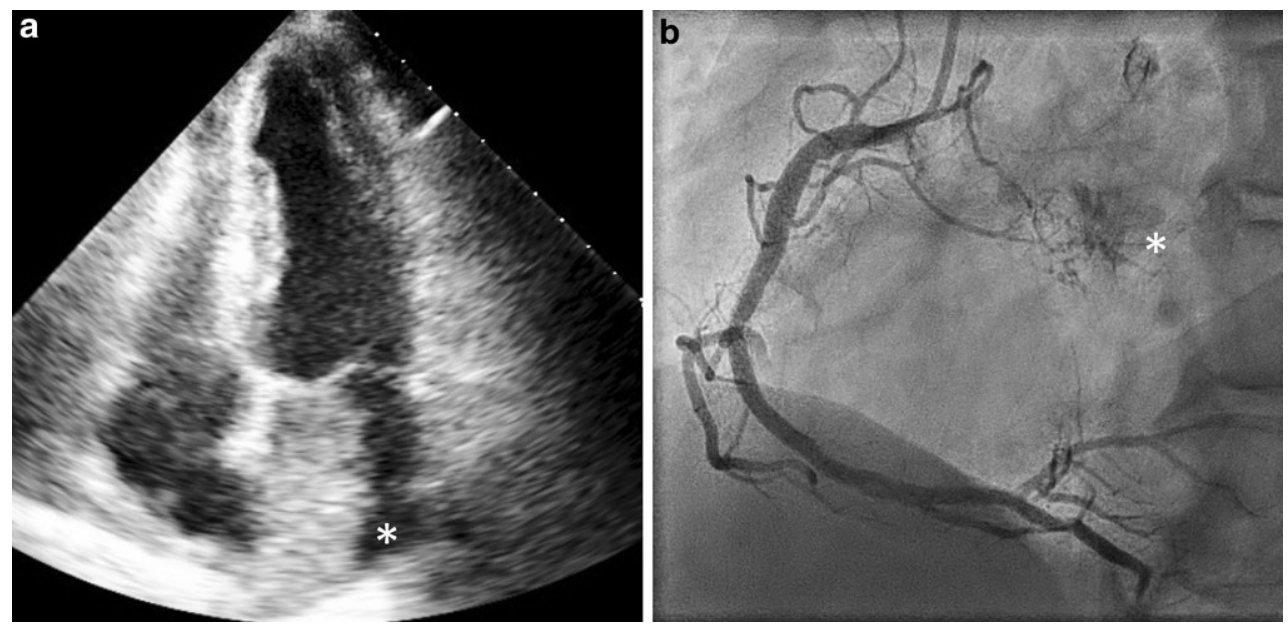